\title{
Círculos de pobreza y finanzas municipales en México*
}

\author{
(Poverty Circles and Municipal Finances in Mexico)
}

Hilario Barcelata Chávez**

\section{RESUMEN}

El desarrollo económico actual de los municipios en México muestra avances, rezagos y retrocesos que se distribuyen de manera desigual en el territorio nacional y al interior de cada municipio, por lo que es pertinente cuestionarse cuáles son los factores que determinan tal panorama. El propósito de este trabajo es evaluar la hipótesis que considera tres factores causales: las políticas de gasto público que permiten complementar el crecimiento económico con el desarrollo humano, el desigual reparto de los recursos públicos que corresponden a cada municipio y la eficiencia de la administración pública municipal. Para ello, se categorizaron los municipios en cuatro grupos, de acuerdo a su situación de progreso o atraso, a fin de analizar sus indicadores financieros y obtener una idea clara de la influencia de las finanzas públicas en el desarrollo municipal.

Palabras clave: pobreza, desigualdad económica regional, finanzas públicas locales, gasto público, desarrollo humano.

Clasificación JEL: H720, O150.

\begin{abstract}
The economic development of Mexican municipalities shows advances, lagging, and backwardness distributed unequally through the national territory, and within each one of them, which brings us to the question: Which are the factors that determine this picture? The objective of this article is look at the hypothesis that considers three causal factors: the public expenditure policy that allows a balance between economic growth and human development, the unequal allocation of public resources of each municipality and the efficiency of the public administration. For this purpose, the municipalities were categorized into four groups according to their progress or backwardness. Then, financial indicators are analyzed to obtain a clear idea of how the public finances influence the municipal's development.
\end{abstract}

Keywords: poverty, regional economic inequality, local public finance, public expenditure, human development.

JEL classification: H720, O150.

\footnotetext{
* Fecha de recepción: 10/01/2013. Fecha de aprobación 12/03/2015.

** Profesor-investigador de la Facultad de Economía de la Universidad Veracruzana. Correo electrónico: hbarcel@hotmail.com.
} 


\section{INTRODUCCIÓN}

El presente trabajo parte de reconocer que uno de los grandes problemas que México enfrenta hoy es la incapacidad histórica de sus municipios para dinamizar por sí mismos sus economías y promover el mejoramiento del nivel de vida de su población. Esto ha propiciado fuertes rezagos económicos y sociales que han acentuado la desigualdad social y regional, lo que conduce a formular la pregunta de investigación: ¿Cuáles son los factores que determinan el rezago económico y social de unos municipios con respecto a otros? Para responderla, se propone la hipótesis de que los factores que determinan que esto suceda, o no, son tres: las políticas de gasto público que permitan una complementación adecuada entre el crecimiento económico y el desarrollo humano, el desigual reparto de los recursos públicos que corresponden a cada municipio y la eficiencia de la administración pública municipal.

Para realizar este estudio se sigue el planteamiento teórico de Ranis y Stewart $(2002 ; 2007)$ del encadenamiento causal entre desarrollo humano y crecimiento económico, con el cual se construye una metodología que, mediante el análisis del producto interno bruto (PIB) per cápita de cada municipio y del Índice de Desarrollo Humano (IDH), identifica la estrecha relación entre crecimiento económico (CE) y desarrollo humano (DH), con lo que es posible reconocer que ambos constituyen procesos que se condicionan y se complementan mutuamente y que el modo en que se materializa la política de gasto público influye en la concreción de ese encadenamiento.

Esta metodología permite categorizar los municipios en cuatro grupos, de acuerdo a su situación de progreso o atraso económico y social. Uno de los grupos, al que se denomina de "círculo virtuoso", abarca a los que tienen las mejores condiciones, tanto de crecimiento económico como de desarrollo humano, mientras que en el otro extremo están los que viven la peor situación, pertenecientes al grupo de "círculo vicioso". Además, dos grupos de municipios en posición intermedia: aquellos que tienen un "sesgo hacia el desarrollo humano", es decir, que tienen avances en éste pero rezagos en el crecimiento económico, y los que tienen un "sesgo hacia el crecimiento", que se caracterizan por sus avances económicos pero se hallan rezagados en su desarrollo humano.

Esta investigación también identifica como una de las causas de los rezagos, o avances municipales, a la profunda desigualdad en el reparto de los recursos públicos necesarios para el desarrollo, por lo cual no es sorprendente que los municipios del círculo virtuoso sean los que más recursos públicos disponen, a 
diferencia de los del círculo vicioso, que padecen una gran escasez de ingresos públicos. Esto evidencia una importante relación directa entre desarrollo económico y recursos públicos, que implica que la mayor disponibilidad de éstos tiene un impacto positivo en el PIB per cápita, en la salud y en la educación de las personas.

Asimismo, se observa que esta relación es más estrecha que la existente entre recursos y crecimiento. Para mostrar lo anterior se ha elaborado otra categorización a partir del monto del PIB municipal para identificar el desigual reparto de la riqueza y su relación con la magnitud de los recursos públicos y la eficiencia con que se da el manejo financiero.

La realización de estos análisis ha requerido la medición, a partir de un conjunto de indicadores de desempeño financiero municipal elaborados por el Instituto Nacional para el Federalismo y el Desarrollo Municipal (INAFED), desagregada del modo en que se ejercen los recursos públicos municipales y el modo en que se asignan y se administran, lo cual tiene repercusión en la calidad del equipamiento urbano y rural, la magnitud de la infraestructura física y las capacidades del capital humano.

Finalmente, se mide la eficiencia de la administración pública municipal a partir de la disponibilidad o ausencia de los reglamentos municipales que corresponde elaborar y aplicar a los ayuntamientos y cuya existencia incrementa el impacto de las políticas públicas que se aplican a nivel local, ya que son instrumentos legales útiles y necesarios para el desarrollo económico. De este modo, es posible establecer que la enorme carencia de normas municipales existente contribuye también a explicar el rezago en el desarrollo de los municipios, ya que limita la capacidad de crear condiciones adecuadas para el desarrollo.

En general, este trabajo confirma cuán importante es la disponibilidad de recursos públicos para impulsar el bienestar social y el hecho de que el crecimiento económico por sí mismo no es suficiente para propiciar el desarrollo humano, lo cual lleva a concluir que la acción del Estado, mediante políticas públicas, es indispensable para impulsar el proceso de desarrollo económico y que es fundamental incrementar los recursos públicos destinados a tal fin.

\section{CONSIDERACIONES TEÓRICAS}

En los últimos años, los gobiernos han realizado un gran esfuerzo por impulsar el crecimiento económico y el desarrollo humano a través de amplios programas de gasto público, a pesar de lo cual en muchos países no se han logrado los obje- 
tivos propuestos. Ello, sin embargo, no debe entenderse de manera lineal en el sentido de que la actividad gubernamental es incapaz de influir en el desarrollo económico, ya que también existen países con trayectorias de crecimiento económico y reducción de la pobreza, que muestran claramente la efectividad de la expansión del gasto público.

En opinión de Ceconi (1998), la teoría no proporciona respuestas claras acerca de la dirección de la causalidad o de la combinación de recursos óptimos para promover el desarrollo. De la misma manera se expresan Lindauer y Velenchik (1992), para quienes los estudios sobre la relación entre el gasto público y el crecimiento no muestran evidencia empírica que corrobore una fuerte correlación entre esas variables. A su parecer, la idea de que el gasto público es un factor determinante de las tasas de crecimiento tiene poco sustento.

Se han hecho múltiples esfuerzos por verificar si el incremento del gasto púbico se asocia a un mejoramiento en el desarrollo humano (educación y salud), pero los resultados son contradictorios, pues, por un lado, existen trabajos que han encontrado una asociación negativa entre eficiencia y niveles de gasto, como los de Gupta, Verhoeven y Tiongson (2001); Jayasuriya y Wodon (2003), y Afonso et al. (2005). En el mismo sentido, Herrera y Pang (2005) han puesto de relieve que los niveles de gasto más elevados están generalmente asociados con índices de eficiencia inferiores y el hecho de que los países en los que la masa salarial es proporcionalmente mayor existe una tendencia a obtener menores índices de eficiencia.

Por otro lado, están los trabajos que muestran una relación positiva entre desarrollo y gasto público, como es el de Xu et al. (2003). E, incluso, otros que no han encontrado ningún efecto significativo (Filmer y Pritchett, 1999).

De igual manera, el interés teórico se ha centrado en ponderar la capacidad del gasto público productivo como instrumento para impulsar el crecimiento económico en el largo plazo, encontrándose evidencia positiva en este sentido en el trabajo de Barro (1990), el cual muestra que el gasto público productivo que realiza el sector público en creación de infraestructura económica es complementario de la inversión privada y tiene efectos sobre el crecimiento económico, por lo que existe una relación positiva entre ese tipo de gasto y el crecimiento de la producción nacional.

A partir de ese mismo concepto, Hernández (2010) encuentra evidencia de que durante el periodo 1980-2009, en México, ni el gasto público productivo (inversión física) ni el capital humano (gasto social) generaron riqueza, dado que no contribuyeron a incrementar las oportunidades de inversión rentables que el 
crecimiento económico provee, porque no se favoreció la creación de la infraestructura económica y social. Por ello, en su perspectiva, no sólo es importante que el gobierno gaste, sino que también es fundamental que lo haga bien.

En la misma perspectiva se ubica el planteamiento de Esfahani y Ramírez (2003), para quienes el gasto público en infraestructura económica y social complementa la formación de capital privado, eliminando los costos de transacción, incrementando la demanda agregada y mejorando las expectativas de los inversionistas. De igual modo opinan Devarajan y Zou (1994), quienes han señalado que los efectos de la inversión pública dependen de la forma en que se financie el gasto del gobierno y de la estructura del sistema financiero, al margen de lo cual consideran que este tipo de gasto efectivamente mejora los resultados que obtienen los empresarios privados.

\section{La teoría del encadenamiento causal entre desarrollo humano y crecimiento económico}

En este conjunto de ideas destaca el planteamiento desarrollado por Ranis y Stewart $(2002 ; 2007)$, base teórica de esta investigación, que establece la estrecha relación entre crecimiento económico (CE) y desarrollo humano (DH) y argumenta que estas variables se condicionan y complementan una a la otra, constituyendo procesos en los que se retroalimentan y se refuerzan mutuamente en el nivel municipal. Este vínculo genera dos grandes encadenamientos en los que el CE provee los recursos para permitir mejoras sustanciales en el DH, para luego este último constituirse en un medio con el que se crean las condiciones para impulsar al primero. El crecimiento va acompañado de desempeños distintos en DH porque está sujeto a un conjunto de factores sociales, políticos e institucionales que determinan la forma en que se asignan los recursos públicos y privados y se distribuye el ingreso. Así, el impacto sobre el DH será mayor si los recursos adicionales que genera el crecimiento mejoran las finanzas públicas, de manera que existan más fondos públicos para aplicarlos en programas que repercutan en aspectos sociales mediante la inversión en capital humano y que, además, se distribuyan de manera más igualitaria a nivel social.

Existe evidencia internacional (Ranis, Stewart y Ramírez, 2000, pp. 200-202) de que un alto CE mejora rápidamente los indicadores de DH y viceversa, pero también se observa que un bajo crecimiento tiende a generar fuertes rezagos en DH, que a su vez generan estancamiento económico. Esto se debe a que el CE impulsa la expansión de la base material necesaria para la satisfacción 
de las necesidades humanas (como las de salud y de educación), lo cual eleva la productividad de las personas; en cambio, su ausencia limita la inversión privada y pública en esos rubros, lo que reduce el potencial de acumulación de recursos productivos. Esto comprueba que CE y DH se fortalecen mutuamente, cuando aparece un círculo virtuoso (reforzamiento positivo) o se debilitan uno al otro, en un círculo vicioso (reforzamiento negativo). Puede resultar también que un mismo ritmo de $\mathrm{CE}$ se traduzca en distintos potenciales de $\mathrm{DH}$, por lo que existen regiones con un sesgo hacia el CE, donde los logros en bienestar son pobres a pesar del avance en materia económica. Y también se han observado situaciones de sesgo hacia el DH, en las que éste es superior a lo alcanzado en materia de crecimiento (Ranis y Stewart, 2007, pp. 33-36).

En este sentido, es fundamental identificar los detalles de las conexiones entre estas variables a nivel municipal, ya que ambas constituyen el sustento primordial para elaborar políticas públicas que permitan detonar un proceso de desarrollo económico local, para lo cual son vitales tanto una acción estatal que impulse dichas políticas, como la magnitud de los recursos públicos disponibles y la eficiencia con que se manejen.

Este planteamiento es apoyado por Amartya Sen (2001), para quien el desarrollo social estimula un crecimiento económico rápido e integrador si se complementa con políticas favorables al mercado que fomenten la expansión económica. Por otro lado, señala también que el crecimiento económico consiste en proporcionar mayores oportunidades al desarrollo humano y debe estar integrado en una comprensión más básica del proceso de desarrollo. Según este autor, la ampliación del gasto público permite estimular la productividad, elevar el crecimiento económico y ampliar las prioridades del desarrollo, además de que contribuye a controlar razonablemente el cambio demográfico.

Lo que parece claro es que el efecto del gasto social sobre el desarrollo económico depende de la calidad de las políticas públicas y los programas que se implementen y de la equidad que conlleven. Es decir, cómo se gasta y en qué se gasta. En este sentido, Scott (2011) señala que esto se debe a que el amplio conjunto de programas de desarrollo social, incluyendo los subsidios al consumo, a la seguridad social, a los productores agrícolas y a la educación superior, padecen un alto grado de regresividad en términos absolutos, porque asignan mayores recursos a los hogares con mayores ingresos. Ello ha contribuido incluso a aumentar la desigualdad del ingreso, debido a un fenómeno al que se le conoce como "trampa de la desigualdad", como resultado de la regresividad con que se aplica el gasto público en programas de desarrollo social en un escenario donde 
inicialmente existen condiciones de alta desigualdad que permite la influencia de cuatro tipos de factores.

\section{CírCulos De POBREZA Y RIQUEZA MUNICIPAl EN MÉXICO}

El planteamiento metodológico de Ranis y Stewart ha sido utilizado para dos estudios a nivel internacional por estos autores. El primero analiza la situación de 66 países integrados en seis regiones (Ranis, Stewart y Ramírez, 2000, pp. 200202), mientras el segundo lo hace con 22 países de América Latina (Ranis y Stewart, 2002). En el caso de México, sólo ha sido utilizado para un análisis a nivel de entidades federativas realizado por Esquivel, López y Vélez (2003) que estudia la dinámica de los círculos de pobreza entre 1950 y 2000. Sin embargo, hasta el momento no se había realizado un estudio a nivel municipal con este enfoque teórico y su metodología, como es el presente, para el cual se ha elaborado una categorización de los municipios del país considerando el valor de su PIB per cápita como medida del crecimiento económico y su IDH como indicador del bienestar municipal, comparando cada uno de ellos con el valor promedio nacional. Con este propósito se calculan las brechas de los valores observados a nivel municipal con respecto a la media nacional de cada variable. Así, la brecha en el PIB municipal se calcula (para un total 2454 municipios) de la siguiente manera:

$$
\mathrm{PIBMpcp}_{n}=\mathrm{PIBMpc}_{i}-\mathrm{PIBMpcp}_{n},
$$

donde

$B P I B M p c_{i}=$ brecha del PIB municipal per cápita del municipio $i$.

$P_{I B M p c_{i}}=$ PIB municipal per cápita del municipio $i$

PIBMpcp $_{n}=$ PIB municipal por habitante promedio nacional.

Y

$$
\operatorname{PIBMpcp}_{n}=n \sum_{i=1}^{n=2454} \operatorname{PIBMpc}_{i} / 2454,
$$

donde

$$
\operatorname{PIBM~p}_{i}=\frac{\mathrm{PIBM}_{i}}{\mathrm{POBM}_{i}}
$$

siendo

$\operatorname{PIBMpc}_{i}=$ PIB municipal por habitante en el municipio $i$.

$P I B M_{i}=$ PIB total del municipio $i$.

$P O B M_{i}=$ población total del municipio $i$. 
Se procede del mismo modo para el cálculo de la brecha del IDH:

$$
\mathrm{BIDHM}_{i}=I D H M_{i}-I D H M p n,
$$

donde

$\operatorname{BIDHM}_{i}=$ brecha de DH del municipio $i$.

$I D H M_{i}=$ IDH del municipio $i$.

$I D H M p n=$ IDH promedio nacional.

Gráfica 1. México. Categorías de municipios por CE y DH, 2005

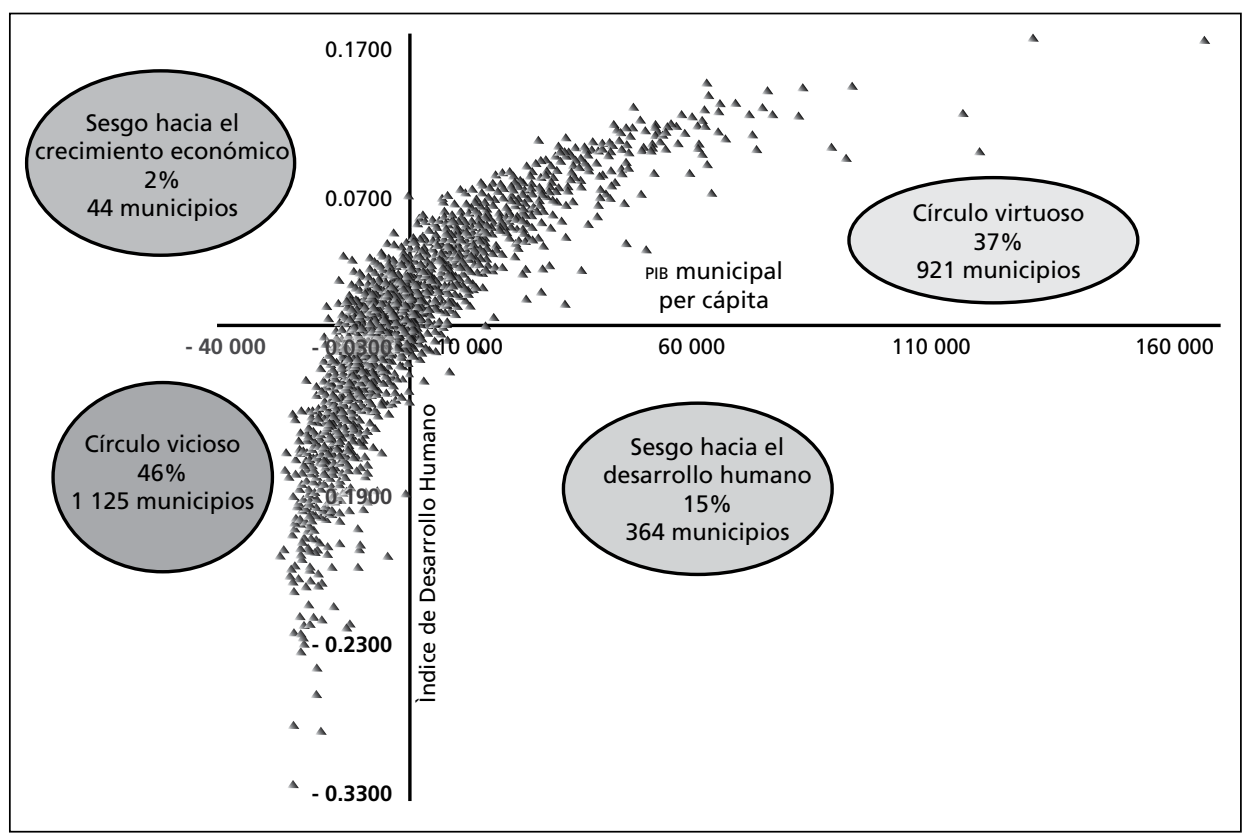

Fuente: Elaboración propia con datos del Instituto Nacional de Geografía y Estadística (2005) y el Programa de las Naciones Unidas para el Desarrollo (2005).

De lo anterior resultan cuatro categorías de municipios caracterizados por un determinado nivel de riqueza personal y un particular nivel de bienestar referido de modo específico a sus condiciones de educación y salud. En la primera, denominada "círculo virtuoso", se localizan aquellos municipios cuyo PIB per cápita y su IDH se encuentran por arriba de la media nacional. En ellos hay un reforzamiento positivo entre ambas variables, por lo que el incremento de una propicia el ascenso de la otra y viceversa. Son 921 municipios (37\% del total) en los cuales se concentra $90 \%$ del PIB y $77 \%$ de la población nacional. 
La segunda categoría, denominada "círculo vicioso", concentra a los municipios con valores de PIB per cápita e IDH por debajo de la media nacional. En éstos existe un reforzamiento negativo entre ambas variables, de modo que el escaso o nulo desempeño de una provoca el estancamiento de la otra y viceversa. Esta relación se convierte en un proceso perverso que deteriora las bases económicas y sociales de la población e impide la existencia de elementos que la capaciten para generar un proceso de desarrollo endógeno que permita superar la situación de atraso y marginación en que viven las personas. En otras palabras, los municipios que se encuentran en estas condiciones son incapaces de superar por sí mismos su atraso generalizado. Se trata de un conjunto de 1125 los municipios ( $46 \%$ del total), los cuales apenas alcanzan a contribuir con $3.3 \%$ del PIB y abarcan $11.4 \%$ de la población del país.

Figura 1. México. Municipios según su situación de desarrollo, 2005

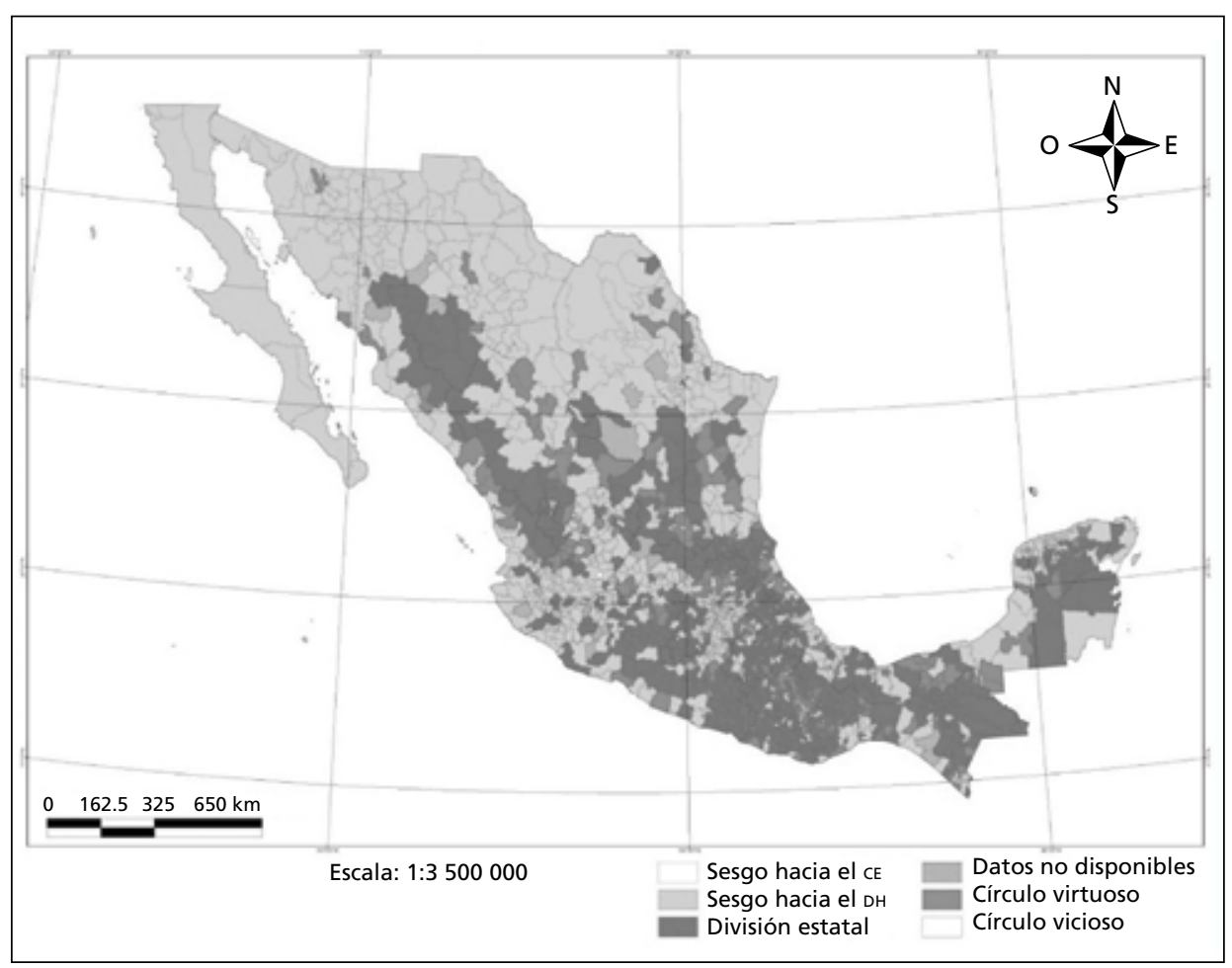

Fuente: Estimaciones propias con datos del Programa de las Naciones Unidas para el Desarrollo (2005) y del Instituto Nacional de Estadística y Geografía (2009b). 
Una tercera categoría es la de los municipios con "sesgo hacia el crecimiento económico", cuyo IDH es menor a la media nacional pero con un PIB per cápita por encima. En este caso, el CE tiene un dinamismo similar al de los municipios de círculo virtuoso, sin embargo, no es suficiente para impulsar el DH, el cual es semejante al de los del círculo vicioso. Esto significa que el nivel de bienestar es pobre en comparación a lo que se ha alcanzado en materia económica. En esta categoría se ubican 44 municipios ( $2 \%$ del total) con apenas $0.5 \%$ del PIB y $0.9 \%$ de la población nacional.

El cuarto grupo es de los municipios con "sesgo hacia el desarrollo humano", con un IDH mayor a la media nacional pero un PIB municipal per cápita menor. En ellos, el nivel de bienestar social alcanzado por la población es análogo al de los municipios de círculo virtuoso, pero este logro no es suficiente para impulsar el CE, el cual es similar al de los municipios de círculo vicioso. Se trata de 364 municipios (15\% del total) que contribuyen con $3.3 \%$ del PIB y $6.3 \%$ de la población del país.

\section{GASTO PÚBLICO Y CÍRCULOS DE POBREZA Y RIQUEZA}

Para profundizar el análisis y poder observar el modo en que la situación de cada grupo se relaciona con la disponibilidad de recursos públicos y el manejo que de ellos se hace, se requiere establecer la magnitud y el comportamiento de un conjunto de datos relativos a las finanzas públicas municipales. Lamentablemente, no se dispone de información sobre esta variable para todos los municipios incluidos en la categorización previa. Es el caso de 604 municipios de cuatro estados: 532 de Oaxaca, 19 de Puebla, 12 de Chiapas y 10 de Jalisco. Esta carencia de datos resulta relevante porque puede entenderse como resultado de un manejo inadecuado de sus finanzas públicas, lo que conduce a que no entreguen sus cuentas públicas o que éstas no hayan sido aprobadas por la legislatura del estado respectivo. Por esa razón, el Instituto Nacional de Estadística y Geografía (INEGI) no registra sus datos financieros. También es notorio el hecho de que estos municipios pertenezcan al grupo de círculo vicioso y se ubiquen en estados que se caracterizan por sus altos niveles de pobreza, lo cual permite corroborar parcialmente que los municipios pobres tienen problemas financieros de gran magnitud, lo que muy probablemente es la causa de su pobreza.

Por lo anterior, se recalcularon los indicadores de desarrollo utilizando

únicamente los 1850 municipios para los cuales si está disponible su información financiera, eliminando los 604 mencionados. Al modificarse el promedio de 
las variables involucradas, los grupos se modifican ligeramente, salvo en el caso del círculo vicioso, para el cual la proporción de municipios se reduce de $46 \%$ a $37 \%$ del total.

Con este nuevo cálculo, quedan ubicados en el grupo de círculo virtuoso 659 municipios, que concentran $88.4 \%$ del PIB nacional, $75.7 \%$ del gasto público ejercido por los municipios y $74.9 \%$ de la población del país. El grupo de círculo vicioso está compuesto ahora por 691 municipios, los cuales apenas contribuyen con $4.7 \%$ del PIB, ejercen $12.7 \%$ del gasto público municipal y abarcan $11.7 \%$ de la población. En el grupo de sesgo hacia el crecimiento económico se ubican 117 municipios, con apenas $1.7 \%$ del PIB, $2.6 \%$ del gasto público y $2.4 \%$ de la población. Y en el grupo con sesgo hacia el desarrollo humano hay 383 municipios, con $5.2 \%$ del PIB, 9.8\% del gasto público y $10.2 \%$ de la población.

Como se observa, los municipios más ricos concentran la mayor cantidad de la producción nacional y de los recursos públicos, mientras que los más pobres contribuyen muy poco en materia económica y tienen una disponibilidad financiera muy limitada. Las causas que explican la situación de estos municipios están relacionadas con la dotación de factores de la producción a nivel local, como la calidad de la tierra, el equipamiento e infraestructura y el capital humano. Y la magnitud y calidad de estos factores depende en buena medida de la cantidad de recursos públicos que tienen sus gobiernos y la manera en que los asignan y los administran.

Gráfica 2. México. PIB, gasto público y población según situación de desarrollo municipal, 2005

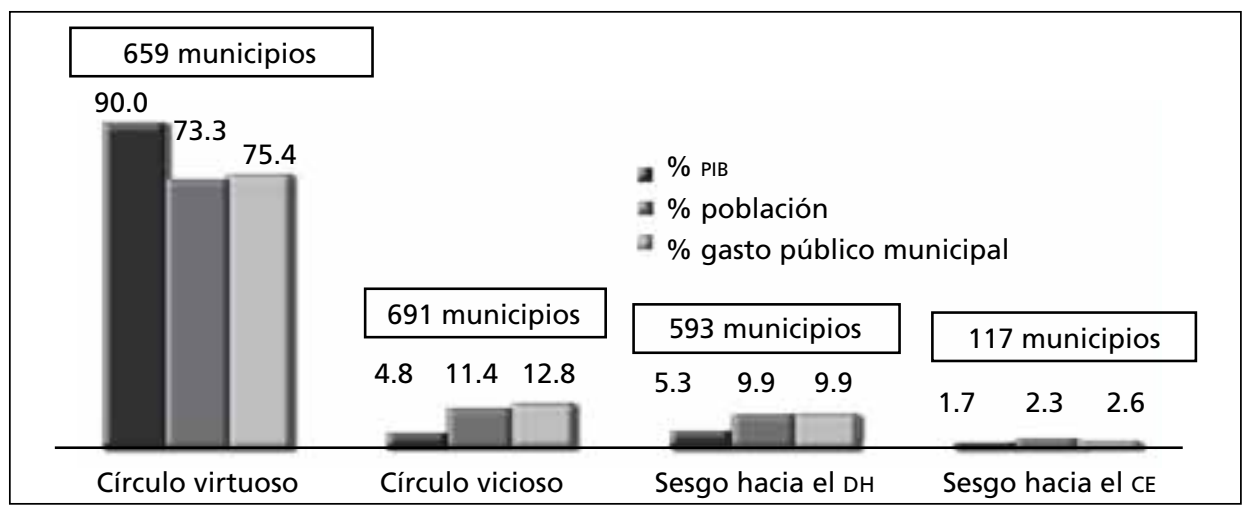

Fuente: Elaboración propia con datos del Instituto Nacional de Geografía y Estadística (2005) y el Programa de las Naciones Unidas para el Desarrollo (2005). 


\section{DESIGUALDAD MUNICIPAL Y DESEMPEÑO FINANCIERO}

Para explicar las causas que determinan las desigualdades económicas y sociales entre los municipios del país es necesario analizar la cantidad de recursos públicos que tienen sus gobiernos y la manera en que se asignan y se administran, considerando que esto es un factor que determina las posibilidades de desarrollo a nivel local por su impacto en la calidad del equipamiento urbano y rural, la magnitud de la infraestructura física y las capacidades del capital humano, tal como lo proponen Ranis y Stewart $(2002 ; 2007)$. Además, todo ello impacta en el aprovechamiento de la dotación original de los factores de la producción e influye en la competitividad de cada región. Los indicadores financieros de los cuatro grupos de municipios propuestos dan una idea clara de la influencia de las finanzas públicas en el crecimiento y desarrollo económico.

\section{1. Índice de autonomía financiera}

Como una primera aproximación al concepto de autonomía financiera se calcula en primer lugar el índice de autonomía financiera en su forma más simple y tradicional, entendido como la proporción del gasto público que los municipios cubren con ingresos propios, lo cual da cuenta de su capacidad para explotar fuentes de ingreso propias, pero además indica en qué medida pueden cubrir sus gastos totales sin la intervención de otros niveles de gobierno.

El indicador se calcula de la siguiente manera:

$$
I A F_{i}=\left(\frac{I P_{i}}{G T_{i}}\right) 100
$$

donde

$I A F_{i}=$ autonomía financiera del municipio $i$.

$I P_{i}=$ ingresos propios del municipio $i$.

$G T_{i}=$ gasto público total del municipio $i$.

\begin{tabular}{l|c}
\hline \multicolumn{2}{c}{ Índice de autonomía financiera } \\
\hline Grupo & Valor (\%) \\
\hline Círculo virtuoso & 18.0 \\
\hline Círculo vicioso & 4.1 \\
\hline Sesgo hacia el CE & 12.4 \\
\hline Sesgo hacia el DH & 6.8 \\
\hline
\end{tabular}


Según puede observarse, los municipios en círculo virtuoso cuentan con una mayor capacidad para cubrir su gasto con ingresos propios, mientras que este indicador es sumamente bajo para el grupo de círculo vicioso. Puede deducirse que esto se debe a que la mayor disponibilidad de ingresos propios propicia una considerable capacidad para influir en el CE y el DH, aunque es muy posible que esta influencia sea más importante sobre el primero que sobre el segundo, pues los municipios con sesgo hacia el crecimiento muestran una autonomía superior comparados con los de sesgo hacia el desarrollo. De lo anterior puede afirmarse que a mayor autonomía, mayores son las posibilidades de obtener CE y DE y que cuando los efectos son de menor magnitud, la influencia es mayor en el primero que en el segundo

\section{Gráfica 3. México. Índice de autonomía financiera municipal,} según situación de desarrollo

(porcentaje del gasto público total cubierto con ingresos propios)

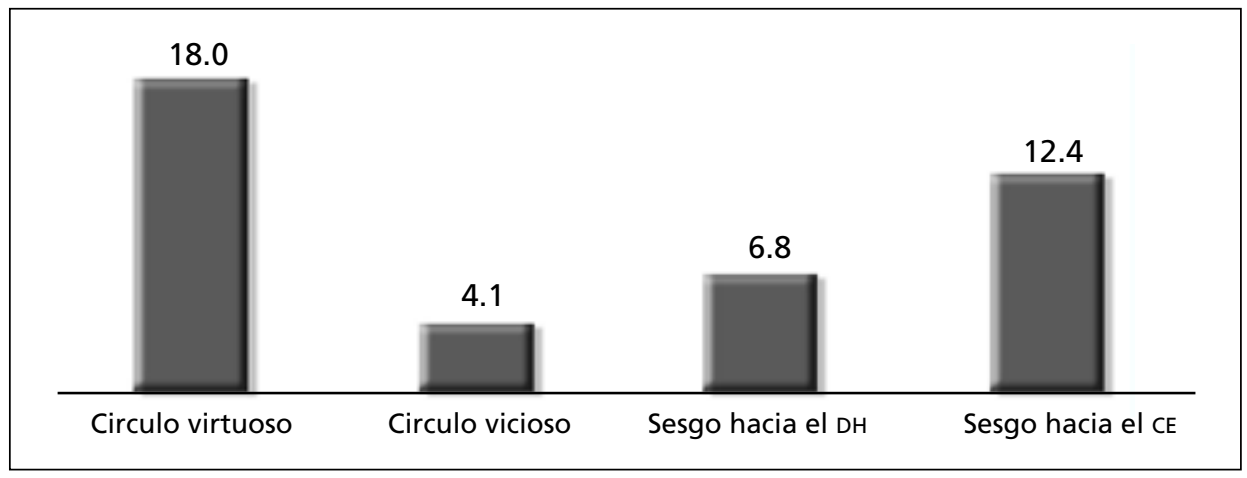

Fuente: Elaboración propia con datos del Instituto Nacional de Geografía y Estadística (2005) y el Programa de las Naciones Unidas para el Desarrollo (2005).

\section{2. Índice de autonomía para financiar gasto operativo}

El indicador del apartado anterior, que compara los ingresos propios con el gasto total, es insuficiente para explicar la autonomía, puesto que debido al arreglo institucional que sustenta el federalismo fiscal, los ingresos propios solos no pueden constituir el total de los ingresos públicos de un municipio y, por lo mismo, nunca podrán representar el cien por ciento del gasto total. Además, en esos términos, un incremento de la autonomía financiera no significaría necesariamente una mejora en el municipio, toda vez que el indicador puede modificarse 
si el gasto total baja como resultado de una disminución en las participaciones o aportaciones federales (Peña y Bojórquez, 2012, p. 8).

En consecuencia, se propone una forma más refinada y precisa de comprender la autonomía financiera comparando la suficiencia de los municipios para financiar su gasto corriente con ingresos propios, lo cual constituye un indicador más objetivo de la capacidad real de un municipio para atender al menos el gasto que le permita operar de manera normal y ordinaria (Peña y Bojórquez, 2012 , p. 8). En este caso, se calcula entonces el que se ha denominado, en este estudio, indice de autonomía para financiar gasto operativo, el cual expresa el poder de los ingresos propios de un municipio para cubrir su gasto corriente. Aunque éste se refiere a los recursos para desarrollar las actividades cotidianas y operar las oficinas gubernamentales, como sueldos, salarios, servicios generales, entre otros, es importante considerar que este tipo de gasto también incluye programas como becas, apoyos a microempresas, alumbrado público, desarrollo social, etcétera, que influyen en el desarrollo municipal (Otero, 2011). En este sentido, este indicador estaría mostrando también cuánta capacidad tiene cada municipio para financiar gasto para el desarrollo que no es gasto de inversión.

Este indicador se calcula así:

donde

$$
I A F G O_{i}=\left(\frac{I P_{i}}{G C_{i}}\right) 100,
$$

$$
\begin{aligned}
I A F G O_{i}= & \text { índice de autonomía para financiar gasto operativo del } \\
& \text { municipio } i . \\
I P_{i}= & \text { ingresos propios del municipio } i . \\
G C_{i}= & \text { gasto corriente del municipio } i .
\end{aligned}
$$

\begin{tabular}{l|c}
\hline \multicolumn{1}{c}{ Índice de autonomía para financiar gasto operativo } \\
\hline \multicolumn{1}{c|}{ Grupo } & Valor (\%) \\
\hline Círculo virtuoso & 29.5 \\
\hline Círculo vicioso & 8.3 \\
\hline Sesgo hacia el CE & 21.2 \\
\hline Sesgo hacia el DH & 13.0 \\
\hline
\end{tabular}

Nuevamente se observa cómo los ingresos propios están asociados a mayores CE y DH, con una influencia más notoria en aquél, dado que los grupos que presentan los valores más elevados son los de círculo virtuoso y sesgo hacia el crecimiento. 
Gráfica 4. México. Índice de autonomía para financiar gasto operativo, según situación de desarrollo

(porcentaje del gasto corriente municipal cubierto con ingresos propios)

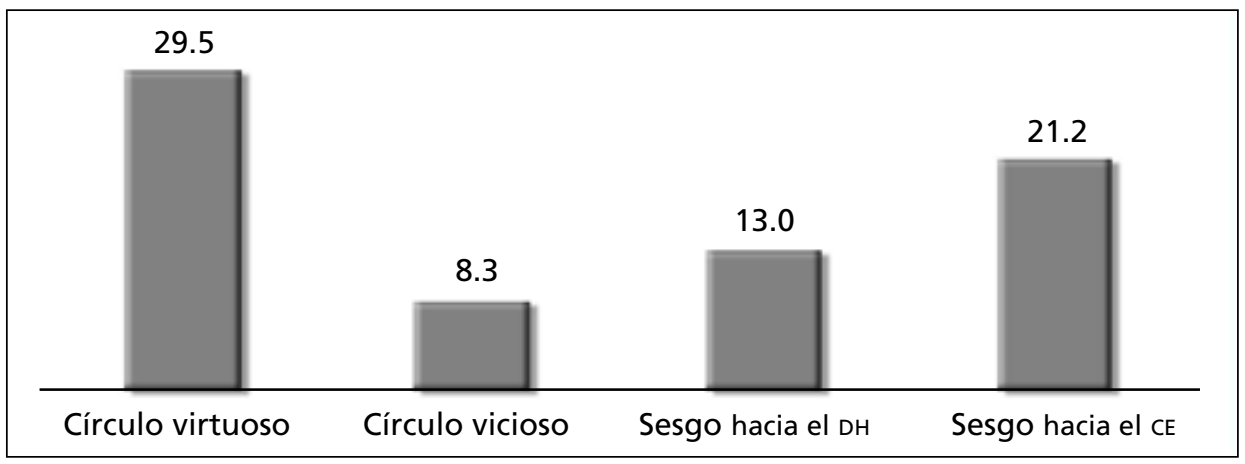

Fuente: Elaboración propia con datos del Instituto Nacional de Geografía y Estadística (2005) y el Programa de las Naciones Unidas para el Desarrollo (2005).

\section{3. Índice de eficiencia recaudatoria local}

Como se ha visto en los apartados anteriores, la magnitud de los ingresos propios está relacionada positivamente con la mayor capacidad financiera de los municipios para solventar su gasto, por lo que puede esperarse que aquellos con una mayor recaudación se encuentren en mejor posición para promover el desarrollo municipal. Un indicador complementario para corroborar esta afirmación es el índice de eficiencia recaudatoria local, que expresa el valor de los ingresos propios totales como proporción del PIB municipal y tiene como propósito medir de manera relativa la magnitud de la recaudación total (tributaria y no tributaria) de cada municipio en relación a la riqueza generada en su interior, para validar el análisis comparado.

La formulación es de la siguiente manera:

$$
\operatorname{IERM}_{i}=\left(\frac{I T_{i}}{P I B M_{i}}\right) 100
$$

donde

$I E R M_{i}=$ índice de eficiencia recaudatoria local del municipio $i$.

$I T_{i} \quad=$ ingresos públicos totales del municipio $i$.

$\operatorname{PIBM}_{i}=$ PIB del municipio $i$. 


\begin{tabular}{l|c}
\hline \multicolumn{2}{c}{ Índice de eficiencia recaudatoria local } \\
\hline \multicolumn{1}{c}{ Grupo } & Valor (\%) \\
\hline Círculo virtuoso & 0.59 \\
\hline Círculo vicioso & 0.33 \\
\hline Sesgo hacia el CE & 0.70 \\
\hline Sesgo hacia el DH & 0.41 \\
\hline
\end{tabular}

Los resultados confirman que un mayor poder recaudatorio local está relacionado positivamente con el crecimiento y la mejor situación económica, tanto en el sentido de que una mayor recaudación ejerce efectos sobre la actividad productiva, como de que esa actividad incrementada genera mayor recaudación.

\section{4. Índice de eficiencia tributaria}

Asimismo, puede observarse que de modo específico los municipios en mejor situación cobran mejor sus impuestos, lo cual es posible medir con el índice de eficiencia tributaria, que expresa el valor de los impuestos propios recaudados como proporción del PIB municipal, sin dejar de lado la consideración de que éste no representa la recaudación potencial de los impuestos locales y, por lo tanto, es más bien un indicador para establecer magnitudes que permitan la comparación entre municipios, porque obviamente no expresa qué proporción de cada base gravable se recauda.

El cálculo es como sigue:

$$
\operatorname{IETM}_{i}=\left(\frac{I I_{i}}{P I B M_{i}}\right) 100,
$$

donde

$\operatorname{IETM}_{i}=$ índice de eficiencia tributaria local del municipio $i$.

$I I_{i} \quad=$ ingresos por impuestos locales del municipio $i$.

$\operatorname{PIBM}_{i}=$ PIB del municipio $i$.

\begin{tabular}{l|c}
\hline \multicolumn{2}{c}{ Índice de eficiencia tributaria } \\
\hline Grupo & Valor (\%) \\
\hline Círculo virtuoso & 0.24 \\
\hline Círculo vicioso & 0.10 \\
\hline Sesgo hacia el CE & 0.21 \\
\hline Sesgo hacia el DH & 0.13 \\
\hline
\end{tabular}


Como era de esperarse, por lo que se ha expuesto respecto a la relación entre ingresos públicos y desarrollo, los municipios en mejor situación tienen una mayor eficiencia tributaria, así como aquellos que se ubican en sesgo hacia el crecimiento, en tanto que la más baja eficiencia es propia de los que se encuentran en círculo vicioso y en sesgo hacia el desarrollo.

Gráfica 5. Índices de eficiencia recaudatoria local y tributaria municipal, según situación de desarrollo

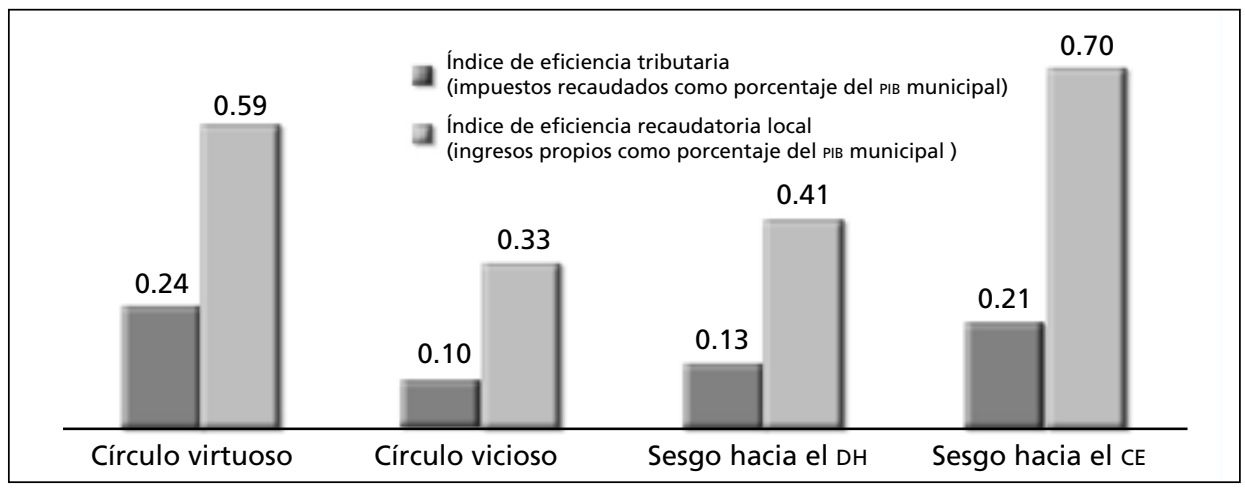

Fuente: Elaboración propia con datos del Instituto Nacional de Geografía y Estadística (2005) y el Programa de las Naciones Unidas para el Desarrollo (2005).

\section{5. Índice de gasto público municipal}

También es importante estudiar cómo es el gasto público que ejercen los gobiernos locales comparado con el progreso de los municipios. Para evaluar este aspecto se ha desarrollado, para este trabajo, el índice de gasto público municipal, que mide la magnitud del gasto de los municipios como proporción de su PIB, dimensionándolo para conocer su importancia en términos del tamaño de la economía municipal, lo que, además, permite realizar un ejercicio de comparación.

$\mathrm{Su}$ cálculo es como sigue:

$$
I G T M_{i}=\left(\frac{G T M_{i}}{P I B M_{i}}\right) 100
$$

donde

$I G T M_{i}=$ índice de gasto público total del municipio $i$.

$G T M_{i}=$ gasto público total del municipio $i$.

$\operatorname{PIBM}_{i}=$ PIB del municipio $i$. 
En este análisis se puede observar un fenómeno contradictorio, ya que los municipios que tienen relativamente más recursos públicos son los que se encuentran en peor situación, lo cual es inverso a lo que se espera que suceda, dado que la mayor disponibilidad de recursos, como se vio antes, se refleja en un mayor nivel de desarrollo.

Así, los municipios en círculo vicioso muestran un valor promedio de $8.4 \%$, mientras que en los del círculo virtuoso es de sólo 3.7\%. Es decir, el gasto municipal como proporción de la riqueza local es mayor en los municipios más pobres que en los más desarrollados y, por tanto, debería reflejarse en un mejor escenario económico y social, pero no es así. Esto conduce a pensar que su situación de atraso está asociada, entonces, a un uso inadecuado de los recursos públicos, propiciando que el efecto que podría derivarse del tamaño del gasto municipal se diluya. En cambio, en los municipios con mayor nivel de desarrollo, el gasto público parece ser mucho más rentable, lo que probablemente se explique por una mejor administración (Cabrero, 2004).

\section{6. Índice de gasto de inversión}

También se ha calculado un índice de gasto de inversión para medir el volumen del gasto de inversión como proporción del PIB municipal y dimensionar su magnitud relativa, lo que valida el análisis comparado. Este tipo de gasto se integra con la suma de la inversión financiera, el gasto en obras públicas y acciones sociales, y los egresos por adquisiciones de bienes muebles e inmuebles e indica la capacidad de un municipio para crear o comprar activos fijos y, por lo mismo, para proveer en menor o mayor medida bienes y servicios públicos.

Su cálculo es el siguiente:

$$
\operatorname{IGIM}_{i}=\left(\frac{G I M_{i}}{P I B M_{i}}\right) 100,
$$

donde

$I G I M_{i}=$ índice de gasto de inversión del municipio $i$.

$G I M_{i}=$ gasto de inversión del municipio $i$.

PIBM $_{i}=$ PIB del municipio $i$.

\begin{tabular}{l|c}
\hline \multicolumn{2}{c}{ Índice de gasto de inversión } \\
\hline \multicolumn{1}{c}{ Grupo } & Valor (\%) \\
\hline Círculo virtuoso & 0.9 \\
\hline Círculo vicioso & 3.2 \\
\hline Sesgo hacia el CE & 2.1 \\
\hline Sesgo hacia el DH & 1.6 \\
\hline
\end{tabular}


Si se considera que este tipo de gasto es el que tiene mayor capacidad para potenciar el CE y el DH, se esperaría que los valores más altos se encontraran en los municipios de mejor situación y los más bajos en los de menor desarrollo, pero sucede exactamente lo contrario: los municipios en círculo vicioso tienen un promedio de $3.2 \%$, mientras que los del círculo virtuoso, $0.9 \%$. Incluso de manera individual se observa que los municipios con mayor capacidad de inversión son precisamente los que se encuentran en círculo vicioso.

Gráfica 6. México. Índices de gasto público municipal y de gasto de inversión, según situación de desarrollo

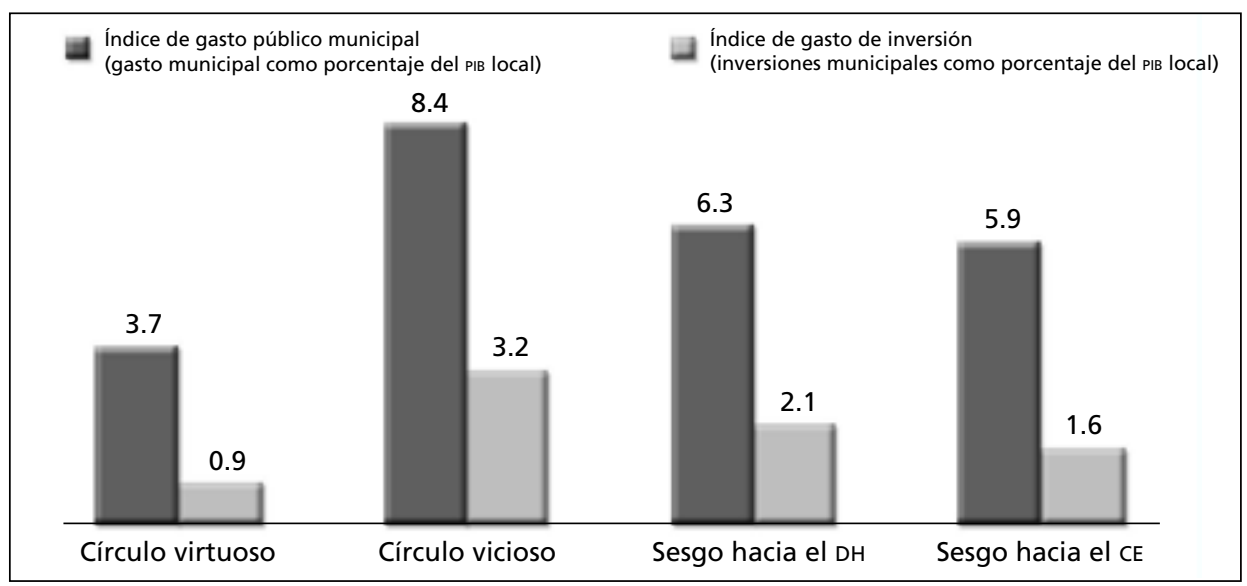

Fuente: Elaboración propia con datos del Instituto Nacional de Geografía y Estadística (2005) y el Programa de las Naciones Unidas para el Desarrollo (2005).

\section{7. Índice de inversión total}

La misma situación descrita en el apartado anterior se observa al calcular el índice de inversión total. Este indicador expresa la magnitud de la inversión física y el gasto social que realiza el municipio como proporción de su gasto total. Este rubro incluye la inversión financiera, el gasto en obras públicas y acciones sociales, y los egresos por adquisiciones de bienes muebles e inmuebles.

Su cálculo se realiza de la siguiente manera:

$$
I I T M_{i}=\left(\frac{G I M_{i}}{G T M_{i}}\right) 100,
$$


donde

$\operatorname{IITM}_{i}=$ índice de inversión total del municipio $i$.

$G I M_{i}=$ inversión física y gasto social del municipio $i$.

$G T M_{i}=$ gasto total del municipio $i$.

\begin{tabular}{l|c}
\hline \multicolumn{2}{c}{ Índice de inversión total } \\
\hline Grupo & Valor (\%) \\
\hline Círculo virtuoso & 25.4 \\
\hline Círculo vicioso & 36.5 \\
\hline Sesgo hacia el CE & 35.1 \\
\hline Sesgo hacia el DH & 28.4 \\
\hline
\end{tabular}

Los resultados indican que los municipios en círculo vicioso se encuentran en mejor situación, ya que el valor promedio de este indicador para ellos es de $36.5 \%$, en tanto que para los de círculo virtuoso es de $25.4 \%$. Es decir, tampoco en este caso, en el que los rubros con mayor capacidad para impulsar el desarrollo representan una proporción elevada del gasto, los municipios en peor situación logran alcanzar resultados positivos, lo cual se debe muy probablemente a un desperdicio de recursos.

\section{8. Índice de inversión social}

En el cálculo de los dos indicadores anteriores se uso la noción más amplia de gasto de inversión, que incluye los egresos por compras de bienes muebles e inmuebles, y si bien es cierto que este rubro de gasto puede tener influencia en el desarrollo municipal, la realidad es que constituye una variable de menor peso para ese propósito. Por tal razón, se realizó el cálculo del índice de inversión social, que permite conocer cuánto del gasto total se destina a DH y bienestar, para lo cual se considera únicamente el gasto en obras públicas y acciones sociales.

Este indicador se calcula así:

donde

$$
I G S M_{i}=\left(\frac{G O P S M_{i}}{G T M_{i}}\right) 100,
$$

$\operatorname{IGOPSM}_{i}=$ índice de gasto en obras públicas y acciones sociales del municipio $i$.

$\operatorname{GOPSM}_{i}=$ gasto en obras públicas y acciones sociales del municipio $i$.

$G T M_{i} \quad=$ gasto total del municipio $i$. 


\begin{tabular}{l|c}
\hline \multicolumn{2}{c}{ Índice de inversión social } \\
\hline \multicolumn{1}{c}{ Grupo } & Valor (\%) \\
\hline Círculo virtuoso & 23.3 \\
\hline Círculo vicioso & 34.9 \\
\hline Sesgo hacia el CE & 32.8 \\
\hline Sesgo hacia el DH & 26.3 \\
\hline
\end{tabular}

Nuevamente se observa que los municipios del círculo vicioso están en mejores condiciones financieras, lo cual significa que aun teniendo mayor disponibilidad relativa de recursos para inversión se mantienen en situación de pobreza. Es decir, gastar más no garantiza crecimiento y desarrollo, y esto tiene que ver con la eficiencia de la administración pública municipal y la capacidad de las burocracias locales, que es muy cuestionable, sobre todo en los municipios medianos y pequeños (North, 1984; 2006; García, 2014).

Gráfica 7. México. Índices de inversión municipal, según situación de desarrollo

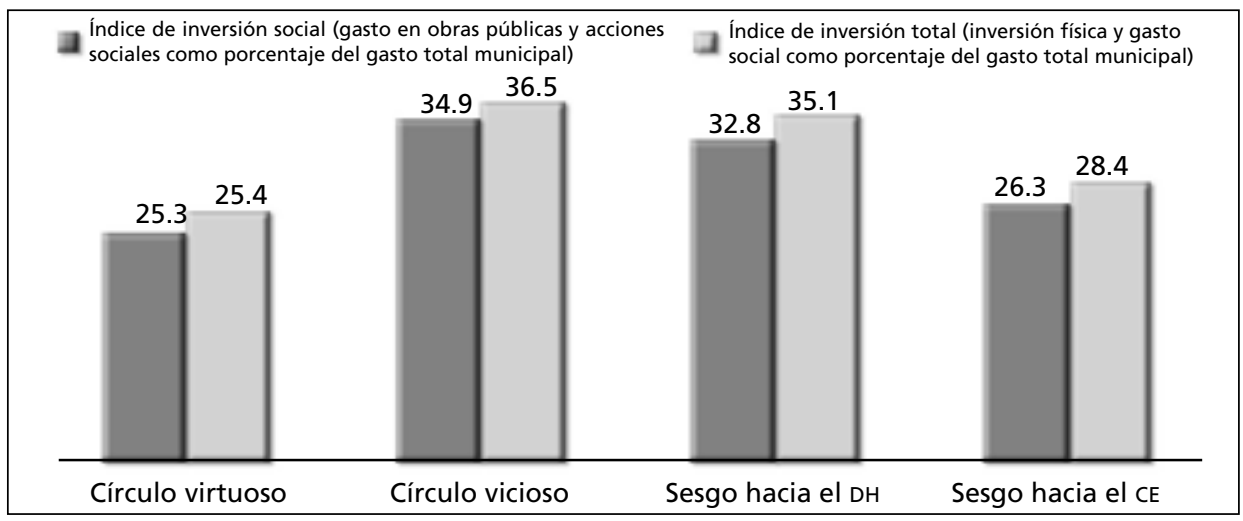

Fuente: Elaboración propia con datos del Instituto Nacional de Geografía y Estadística (2005) y el Programa de las Naciones Unidas para el Desarrollo (2005).

\section{DESIGUALDAD DE LA RIQUEZA MUNICIPAL}

Con el fin de identificar de manera más amplia la desigual distribución de la riqueza a nivel regional entre municipios y profundizar el análisis de la relación entre ésta y las finanzas públicas municipales, se elaboró otra categorización a partir de la riqueza de cada municipio, de acuerdo al PIB de cada uno. De ello resultan seis categorías que dan lugar a un nuevo agrupamiento. El primer grupo ha sido denominado de los "muy ricos" y está compuesto por 25 municipios, 
Cuadro 1. PIB municipal y participación en el PIB y la población nacionales, por grupos de municipios

\begin{tabular}{l|c|c|c}
\hline \multicolumn{1}{c|}{ Grupo } & $\begin{array}{c}\text { PIB municipal promedio } \\
\text { anual (mdp mexicanos) }\end{array}$ & $\begin{array}{c}\text { Porcentaje del PIB } \\
\text { nacional }\end{array}$ & $\begin{array}{c}\text { Porcentaje de la } \\
\text { población nacional }\end{array}$ \\
\hline Muy ricos & 80000 & 36.8 & 26.0 \\
\hline Ricos & 33200 & 15.3 & 12.8 \\
\hline Medio & 16590 & 15.3 & 12.6 \\
\hline Medio bajo & 6000 & 11.1 & 12.3 \\
\hline Pobres & 1800 & 13.5 & 20.3 \\
\hline Muy pobres & 346 & 8.0 & 16.0 \\
\hline
\end{tabular}

cuyo PIB promedio anual es de MXN 80000 mdp a precios constantes de 2005 y que en conjunto concentran $36.8 \%$ del PIB nacional con sólo $26 \%$ de la población.

Le sigue el grupo de los "ricos", cuyo PIB municipal promedio anual es de MXN 33200 mdp, lo que ya denota una gran desigualdad con respecto al anterior, pues su riqueza es de menos de la mitad que la del primer grupo. Estos municipios concentran $15.3 \%$ del PIB nacional y $12.8 \%$ de la población del país. El tercer grupo es el "medio", en el que ubican cincuenta municipios con un PIB municipal promedio anual de MXN 16590 mdp, es decir, más desigualdad, pues esto equivale a la mitad de la riqueza del grupo anterior y a menos de un cuarto de la de los "muy ricos". En conjunto, abracan $15.3 \%$ del PIB nacional y $12.6 \%$ de la población del país. Lo anterior significa que estos tres grupos suman cien mu-

\section{Gráfica 8. México. PIB municipal promedio por grupos \\ (pesos mexicanos constantes de 2005)}

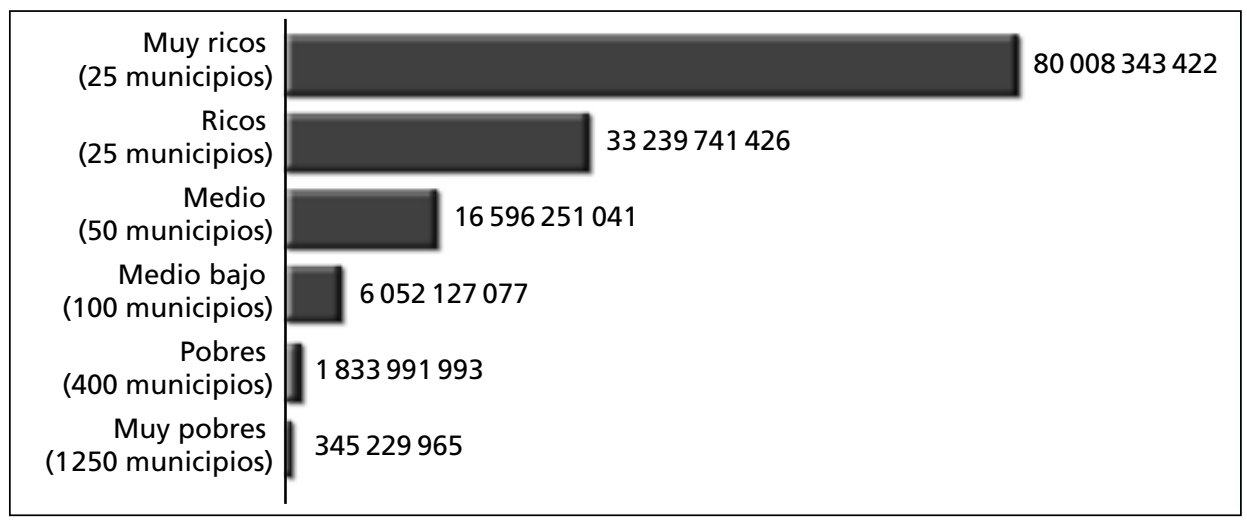

Fuente: Elaboración propia con datos del Instituto Nacional de Geografía y Estadística (2005) y el Programa de las Naciones Unidas para el Desarrollo (2005). 
nicipios, en los que se concentra $70 \%$ de la riqueza que se produce el país, la cual se reparte entre $51.4 \%$ de los mexicanos, es decir, la proporción de riqueza que les corresponde es mayor que la de la población.

Los tres siguientes grupos viven una realidad muy distinta, caracterizada por la pobreza. En el cuarto, denominado "medio bajo" se ubican cien municipios cuyo PIB municipal promedio anual es de sólo MXN 6000 mdp, menos de la mitad que el grupo "medio" y 13 veces menor que el de los "muy ricos". Este grupo produce $11.1 \%$ del PIB nacional y comprende $12.3 \%$ de los habitantes del país. Le sigue el grupo de "pobres", en el que se localizan cuatrocientos municipios; con un PIB municipal promedio anual de sólo MXN 1800 mdp, les corresponde en conjunto $13.5 \%$ de la riqueza nacional y concentran $20.3 \%$ de la población. Finalmente, está el grupo de lo "muy pobres", 1250 municipios con un PIB municipal promedio anual de apenas MXN 346 mdp. A este grupo le corresponde sólo $8 \%$ de la riqueza nacional, pero con $16 \%$ de la población nacional. Estos tres grupos suman 1750 municipios en los cuales, según se ve, la proporción de la riqueza que les corresponde es menor que la de la población. Es decir, poca riqueza y mucha población, lo cual es una fórmula de pobreza.

\section{Gráfica 9. México. PIB per cápita por grupos de municipios}

(dólares a paridad de poder de compra de 2005)

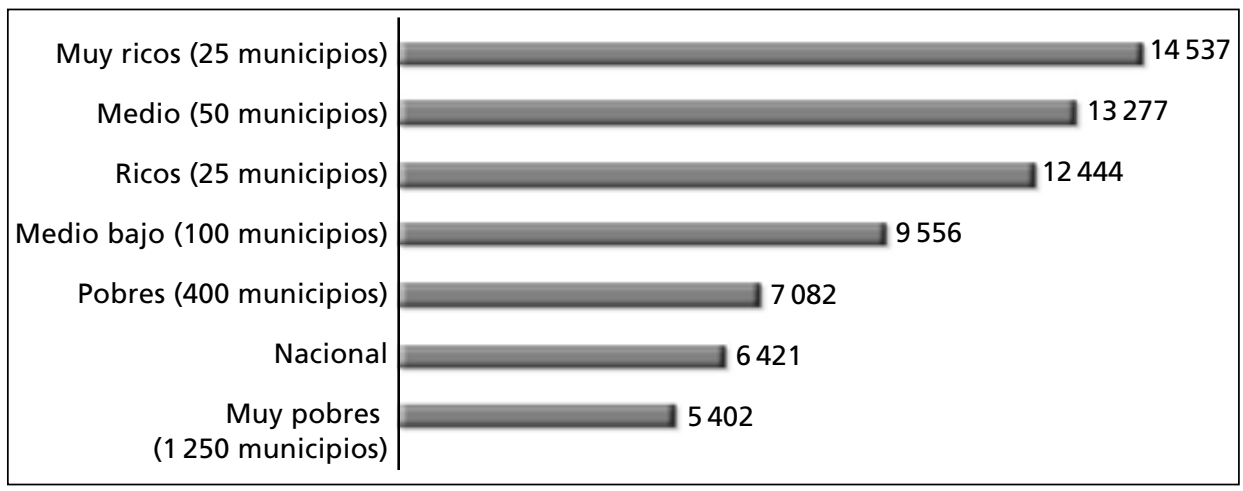

Fuente: Elaboración propia con datos del Instituto Nacional de Geografía y Estadística (2005) y el Programa de las Naciones Unidas para el Desarrollo (2005).

Otra variable que muestra la desigualdad es el PIB municipal per cápita. En el grupo de "muy ricos" es de USD 14537 (paridad de poder de compra de 2005) anuales por persona, seguido por el grupo "medio", con USD 13277 , y el de "ricos", con USD 12444 dólares. Luego vienen los del grupo "medio bajo", 
con USD 9 556; el de "pobres", con USD 7 082, y el de "muy pobres", con apenas USD 5 402, casi tres veces menos que el grupo de los "muy ricos". Este desigual reparto de la riqueza se explica por múltiples factores, uno de los cuales lo constituye el gasto público de los municipios y la efectividad con la que se ejerce.

\section{DESIGUALDAD Y GASTO PÚBLICO}

La profunda concentración de la riqueza y la desigualdad económica que se observa en el ámbito regional en México está relacionada con los montos y el manejo de las finanzas públicas. En el segunda categorización presentada, se observa que el grupo de los "muy ricos" está compuesto por 25 municipios, que concentran $26.5 \%$ del total del gasto público municipal (GPM) del país, con un promedio por municipio de MXN $1518 \mathrm{mdp}$, y 26\% de la población nacional. Le sigue el grupo de los "ricos" (25 municipios) con 12.3\% del MXN, un promedio de MXN 705 mdp y $12.8 \%$ de la población. En tercer lugar están los cincuenta municipios del grupo "medio", con 13\% del GPM, un gasto promedio de MXN 371 mdp y sólo $12.6 \%$ de la población. Esto significa que $51.8 \%$ del total de los recursos públicos municipales a nivel nacional se concentra en sólo cien municipios, en los cuales se localizan $51.4 \%$ de los habiatntes del país.

Cuadro 2. PIB municipal per cápita, GPM y participación en el GPM y la población nacionales, por grupos de municipios

\begin{tabular}{c|r|r|r|r}
\hline Grupo & $\begin{array}{c}\text { 'PIB municipal per } \\
\text { cápita } \\
\text { (dólares) }\end{array}$ & $\begin{array}{c}\text { Gasto público } \\
\text { municipal } \\
\text { (mdp } \\
\text { mexicanos) }\end{array}$ & $\begin{array}{c}\text { Porcentaje del } \\
\text { gasto público } \\
\text { municipal del } \\
\text { país }\end{array}$ & $\begin{array}{c}\text { Porcentaje de } \\
\text { la población } \\
\text { nacional }\end{array}$ \\
\hline Muy ricos & 14537 & 1518 & 26.5 & 26.0 \\
\hline Ricos & 12444 & 705 & 12.3 & 12.8 \\
\hline Medio & 13277 & 371 & 13.0 & 12.6 \\
\hline Medio bajo & 9556 & 165 & 11.5 & 12.3 \\
\hline Pobres & 7082 & 66 & 18.5 & 20.3 \\
\hline Muy pobres & 5402 & 21 & 18.2 & 16.0 \\
\hline
\end{tabular}

En el otro extremo están los tres grupos de municipios en peores condiciones. El llamado "medio bajo" lo constituyen cien municipios que concentran $11.5 \%$ del GPM y tienen un gasto promedio por municipio de MXN 165 mdp. Le sigue el grupo de "pobres", que son cuatrocientos municipios con $18.5 \%$ del GPM 
y un promedio de MXN 66 mdp. En último lugar, los "muy pobres": 1250 municipios, los cuales ejercen 18.2\% del GPM, con un gasto promedio de sólo MXN 21 mdp. Estos tres últimos grupos suman en conjunto 1750 municipios que abarcan $48.6 \%$ de la población y realizan $48.2 \%$ del GPM nacional.

Gráfica 10. México. Participación en el GPM total y en la población nacional, por grupos de municipios

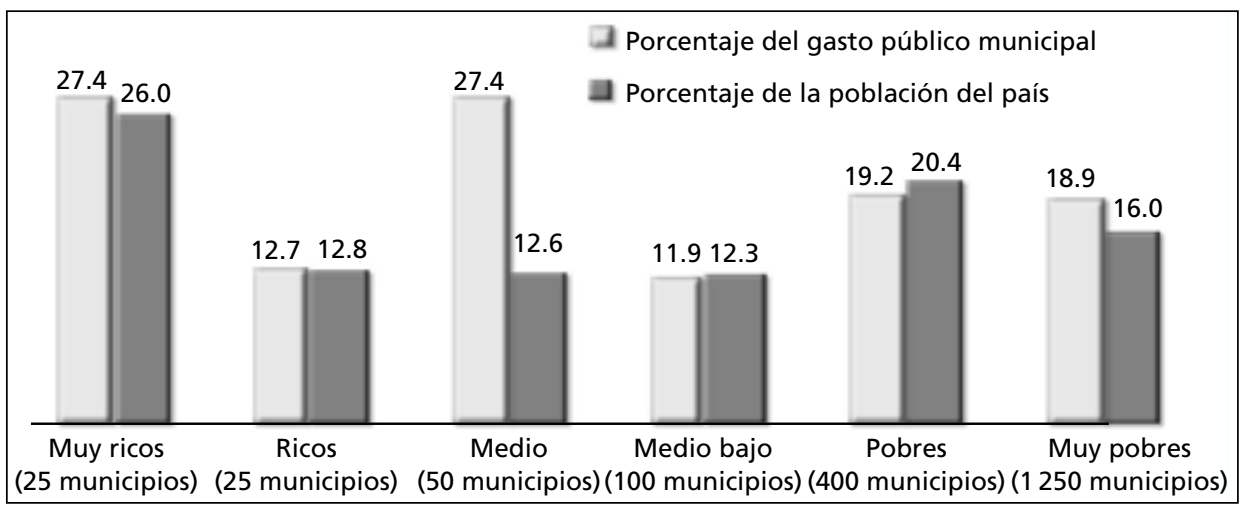

Fuente: Elaboración propia con datos del Instituto Nacional de Estadística y Geografía (2005) y el Programa de las Naciones Unidas para el Desarrollo (2005).

Es importante recordar que aunque los municipios más ricos tienen más recursos para gastar, concentran una gran proporción de los habitantes del país. Por ello, y con el fin de dimensionar la capacidad de los ayuntamientos para atender a su población, se ha calculado el GPM per cápita, esto es, cuántos pesos en promedio se destinan para atender a cada habitante de cada municipio. Se puede ver que el grupo de los "muy pobres" es el que más recursos públicos gasta por persona: un monto de MXN 2224 anuales. En cambio, los municipios de los grupos "ricos" y "muy ricos" tienen un GPM per cápita de MXN 1645 y MXN 1529 , respectivamente. De igual modo se calculó el monto per cápita de las aportaciones federales, que son los recursos que cada municipio recibe de la Federación e incorpora a su gasto para programas destinados a reducir la pobreza o para atender aspectos que impactan en el DH, como el gasto en educación y en salud. Se observa que los municipios "muy pobres" son los que más recursos por persona ejercen: MXN 1 076. Lo mismo sucede con el grupo de "pobres", cuyas aportaciones federales per cápita ascienden a MXN 587. En cambio, los "muy ricos" y "ricos" tienen montos considerablemente más bajos: MXN 296 y MXN 329 por persona, respectivamente. 
Gráfica 11. México. Gasto público municipal per cápita por grupos de municipios (pesos mexicanos corrientes de 2005)

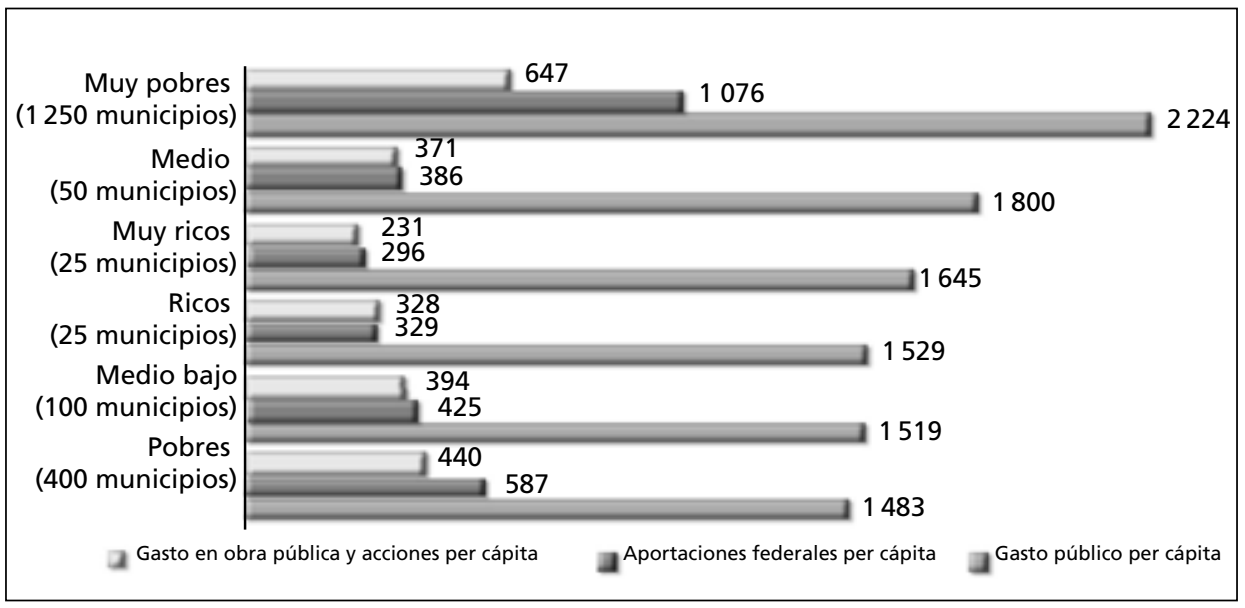

Fuente: Elaboración propia con datos del Instituto Nacional de Estadística y Geografía (2005) y el Programa de las Naciones Unidas para el Desarrollo (2005).

Lo anterior significa que los municipios más pobres gastan más recursos públicos por persona que los ricos, lo cual parece razonable debido a que por su situación de pobreza reciben proporcionalmente más recursos del Fondo de Aportaciones Federales (ramo 33 del Presupuesto de Egresos de la Federación), ya que el método de reparto de éstos considera criterios de pobreza. Por esto, también se esperaría que a lo largo del tiempo la situación de pobreza de estos municipios fuera cambiando, aunque los resultados no indican un avance en su desarrollo. En cambio, los municipios más prósperos destinan montos de gasto público por persona menores, a pesar de lo cual sus resultados en términos de desarrollo son mejores.

De esta manera, es posible concluir que, aunque debería tener alguna influencia en el desarrollo municipal, el gasto público no ejerce ningún efecto, al menos en los municipios menos favorecidos. Pero es sabido que dicho efecto depende no sólo del monto del gasto, sino también, y de manera determinante, del modo en que se administran los recursos y se deciden las asignaciones de gasto intramunicipal (Barcelata y Cuevas, 2013), razón por la que muy probablemente en los municipios más ricos se obtienen mejores resultados con menos recursos, mientras que en los municipios pobres, con más gasto por persona, los resultados son adversos. 


\section{REGLAMENTACIÓN MUNICIPAL Y DESARROLLO ECONÓMICO}

Una forma de lograr una medida de la eficiencia de la administración pública municipal, aunque de manera indirecta, es a través del análisis de la disponibilidad de los reglamentos municipales que les corresponde elaborar y aplicar. Éstos son instrumentos legales útiles y necesarios para el desarrollo económico local porque permiten que el nivel de gobierno más cercano a la sociedad promueva y regule adecuadamente la actividad productiva del municipio, garantice la seguridad de las personas y de su patrimonio, e impulse el desarrollo urbano y mejore el cobro de contribuciones (Cabrero, 2004)

Con el fin de identificar la situación que viven los municipios del país a este respecto, se clasificaron 26 tipos de reglamento en cinco grupos, de acuerdo a los asuntos públicos que regula cada uno, y se procedió a establecer el porcentaje de municipios que cuenta con esa reglamentación vigente.

a) El primer grupo de reglamentos, por su importancia, es el de administración municipal, que se refiere a las normas que regulan el funcionamiento interno de los ayuntamientos y que sirven para mejorar la eficiencia del gobierno municipal. Comprende los ordenamientos sobre nueve materias: reglamento interior del ayuntamiento (que sólo lo tiene $51 \%$ de los municipios del país), reglamento de administración pública municipal (sólo cuentan con él 35\% de los gobiernos municipales); servicios públicos de limpia y sanidad (34\% de los ayuntamientos); cementerios (32\%); obra pública municipal (28\%), transparencia (27\%), alumbrado público $(24 \%)$, planeación $(23 \%)$, archivo municipal $(23 \%)$ y recursos humanos, materiales y financieros (19\%). La existencia de estos ordenamientos está relacionada con el cobro de un conjunto de derechos que puede nutrir de manera importante la recaudación pública y su ausencia tiene un impacto negativo sobre la eficiencia en ese rubro. Es el caso de los siguientes derechos: por servicios de panteones, por servicios de recolección, transporte y disposición final de desechos sólidos, por servicios prestados por la tesorería, por los servicios del registro civil y las contribuciones por mejoras.

b) El segundo tipo de reglamentos es el referido al ordenamiento urbano y el medio ambiente. Éstos influyen en el manejo fiscal del ayuntamiento y en los resultados financieros que obtenga, ya que entre ellos se encuentran aquellos que le permiten mejorar su recaudación de diversos 
impuestos locales relativos a la propiedad inmobiliaria. En este grupo se ubican cinco materias: En primer lugar, catastro municipal, con el propósito de integrar y organizar el funcionamiento del catastro y determinar las obligaciones que en materia inmobiliaria tienen los propietarios o poseedores de los bienes. Este reglamento es importante porque permite identificar la propiedad patrimonial y hacer eficiente el cobro del impuesto predial, la contribución adicional sobre ingresos municipales que se deriva del primero, el impuesto sobre traslación de dominio de bienes inmuebles y los derechos por limpieza de predios no edificados. Es de las contribuciones más importantes que tienen los municipios, sin embargo, sólo $27 \%$ de ellos cuentan con este tipo de norma. También se encuentra aquí la norma relativa a zonificación y uso de suelo, que tiene como propósito instrumentar las políticas de zonificación y densidad para el desarrollo urbano y regular los usos del suelo. Sólo 21\% de los municipios cuentan con ella. De igual modo, los ordenamientos relativos a fraccionamientos y municipalización, para regular las actividades relativas a fraccionamientos, condominios y conjuntos urbanos en el territorio del municipio, cuya existencia impacta en la eficiencia en el cobro del impuesto sobre fraccionamientos, que se recauda por la venta de lotes urbanos; sólo $18 \%$ de los gobiernos municipales lo tienen. También están los reglamentos que se ocupan de la ecología y la protección al ambiente y del ordenamiento ecológico. El primero está vigente en $33 \%$ de los municipios y el segundo en sólo $21 \%$. Su existencia incide sobre la capacidad recaudatoria municipal por su relación con los siguientes rubros: impuesto sobre traslación de dominio de bienes inmuebles, impuesto sobre fraccionamientos, derechos por limpieza de predios no edificados, derechos por la prestación de servicios de supervisión técnica y derechos sobre la explotación de bancos de material.

c) El tercer grupo de reglamentos fundamentales para el desarrollo local es el de aquellos que regulan y fomentan la actividad económica, y comprende los reglamentos sobre siete materias. Una de ellas es mercados y comercios, que sólo está reglamentada en $42 \%$ de los municipios, lo que es importante no solo en sí mismo, sino porque, entre otras cosas, contar con un ordenamiento al respecto es requisito indispensable para que los ayuntamientos puedan solicitar créditos al Banco Nacional de Obras y Servicios Públicos para la construcción de mercados y cen- 
trales de abasto. También se ubican en este grupo los reglamentos atinentes a espectáculos y diversiones públicas, que se puede encontrar en sólo $35 \%$ de los municipios, así como la normatividad referente a expendio de bebidas alcohólicas (50\%), rastro municipal (25\%), expendio de carnes y aves (20\%), actividades industriales y de prestación de servicios privados $(15 \%)$ y el reglamento de la construcción (25\%). La existencia de estas normas influye en la posibilidad de una adecuada recaudación de las siguientes contribuciones: impuesto sobre espectáculos públicos, derechos por registro y refrendo anual de toda actividad económica, derechos a establecimientos cuyo giro sea la enajenación de bebidas alcohólicas realizada total o parcialmente al público en general, derechos por anuncios comerciales y publicidad, derechos por servicios de rastro o lugares autorizados, derechos por obras materiales y derechos por ocupación de inmuebles del dominio público.

d) El cuarto grupo es el relativo a la seguridad y vialidad, compuesto por tres tipos de reglamentos. Aquí se encuentra el único ordenamiento legal presente en la mayoría de los municipios (73\%), que es el bando de policía y buen gobierno. Lo grave es que el $27 \%$ restante (662 municipios) no cuentan con él, a pesar de que se trata del principal instrumento jurídico que pueden expedir los ayuntamientos y que los faculta para normar el orden público, la seguridad de la población, el derecho de propiedad, el ejercicio del comercio y del trabajo, la salud y el medio ambiente. También son parte de este grupo los reglamentos cuyo propósito es organizar el sistema de seguridad pública municipal. Sólo $45 \%$ de los ayuntamientos cuentan con él. Asimismo, las normas sobre tránsito, vialidad y transporte sólo las tienen 33\% de los municipios.

e) Por último está el grupo de reglamentos relativos a la protección civil y la integración social, un aspecto de suma importancia porque las catástrofes naturales que enfrenta el país año con año exigen establecer medidas para evitar los daños. En este ámbito hay seis materias a reglamentar, siendo la más importante la protección civil, con el fin de prevenir, proteger y auxiliar a las personas, su patrimonio y su entorno, ante la posibilidad de un desastre de origen ya sea natural o humano. Esta reglamentación sólo existe en $37 \%$ de los municipios. Otra normatividad importante es la de salud pública, que regula la prestación de los servicios de salud a la población municipal. En este caso, sólo $27 \%$ de los municipios cuentan con ella. De igual modo, se incluyen en este 
grupo las disposiciones sobre bomberos (sólo en $12 \%$ de los municipios), participación ciudadana (24\%), justicia cívica municipal (20\%) e integración social de personas con discapacidad (14\%).

\section{Gráfica 12. México. Porcentaje de gobiernos municipales que cuentan con reglamentación local por tipo de normatividad}

\begin{tabular}{|c|c|c|}
\hline 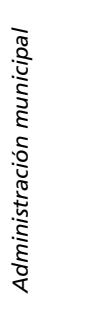 & 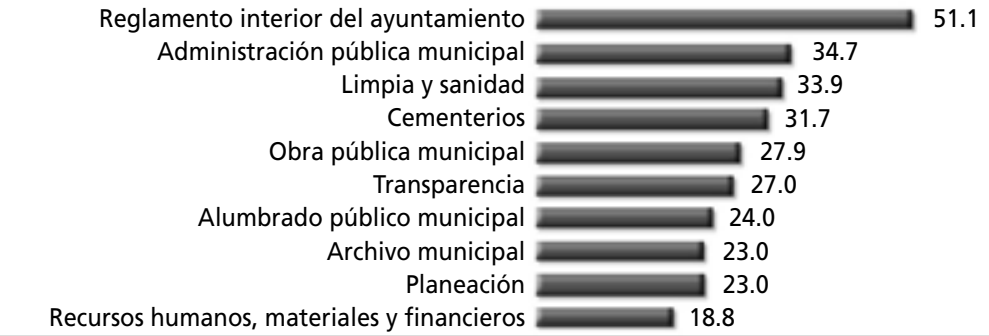 & \\
\hline 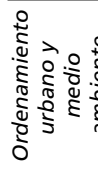 & $\begin{aligned} \text { Ecología y protección al ambiente } & 32.8 \\
\text { Catastro municipal } & 26.7 \\
\text { Zonificación y uso de suelo } & 20.8 \\
\text { Ordenamiento ecológico } & 20.4 \\
\text { Fraccionamientos y municipalización } & 18.1\end{aligned}$ & \\
\hline 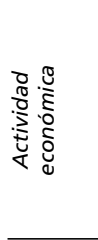 & 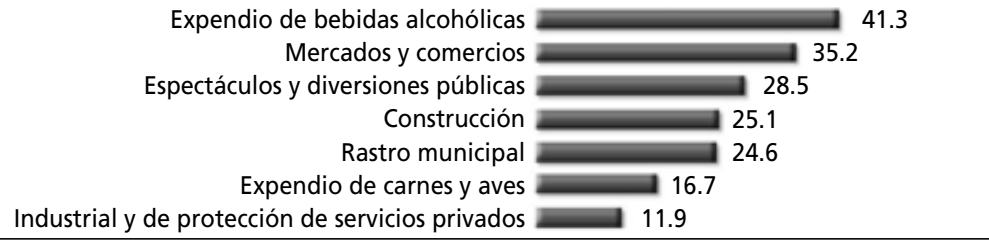 & \\
\hline 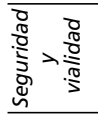 & $\begin{array}{c}\text { Bando de policía y buen gobierno } \\
\text { Seguridad pública } \\
\text { Tránsito, vialidad y transporte } 33.1\end{array}$ & 72.7 \\
\hline 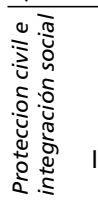 & $\begin{aligned} \text { Protección civil } & \\
\text { Salud pública } & 36.5 \\
\text { Participación ciudadana } & 26.5 \\
\text { Justicia cívica municipal } & 24.0 \\
\text { Integración social de personas con discapacidad } & 14.0 \\
\text { Bomberos } & 12.1\end{aligned}$ & \\
\hline
\end{tabular}

Fuente: Elaboración propia con datos del Instituto Nacional de Estadística y Geografía (2009a).

Según se aprecia, la carencia de normas en los municipios es enorme y sin duda tiene un impacto negativo en su desarrollo, ya que sin estos reglamentos muchos ayuntamientos son incapaces de impulsar el crecimiento económico, mejorar el bienestar social y crear condiciones adecuadas para el desarrollo. 


\section{CONCLUSIONES}

En este trabajo se ha puesto de relieve la profunda desigualdad económica y social entre los municipios del país y se ha identificado la relación que existe entre el atraso económico que vive la mayoría de ellos, los recursos públicos con que cuentan y su capacidad para manejarlos adecuadamente. En este sentido, se ha confirmado la importancia de disponer de recursos públicos para impulsar la expansión productiva y el bienestar social, así como el hecho de que el auge económico por sí mismo no es suficiente para propiciar el desarrollo social, por lo que se concluye que la acción del Estado es indispensable para impulsar el proceso de crecimiento mediante el incremento de los recursos públicos destinados a dicho fin.

Para este análisis, se categorizaron los municipios mediante una metodología que establece cuatro grupos de acuerdo a su situación de progreso o atraso: "círculo virtuoso", "círculo vicioso", "sesgo hacia el CE" y "sesgo hacia el DH". Los indicadores financieros de los municipios agrupados en estas categorías de análisis dan una idea clara de la influencia de las finanzas públicas, pues, según se ha podido observar, la mayor disponibilidad de ingresos propios influye sobre el CE y el DH de manera considerable. De igual modo, se corrobora que una amplia autonomía financiera municipal genera mayores posibilidades en este sentido, toda vez que el mayor poder recaudatorio local está vinculado con la dinámica económica; no sólo porque la expansión de la actividad productiva genera mayor recaudación, sino también porque una más grande disponibilidad de recursos fiscales permite impulsar el $\mathrm{CE}$, incluso en aquellos casos en que existe rezago social.

Otro aspecto destacable es que los municipios en peor situación son aquellos que disponen relativamente de más recursos públicos, pues se observa que el gasto municipal como proporción de la riqueza local es mayor para los municipios más pobres, lo cual conduce a pensar que su situación de atraso está asociada a un uso inadecuado de la hacienda pública.

De igual modo se ha detectado que el gasto municipal es mucho más rentable en los municipios más desarrollados. Esto se deriva del cálculo de la magnitud del gasto de inversión, el de inversión total y el de inversión social, cada uno como proporción del PIB municipal. Este tipo de gasto indica la magnitud de la inversión que realiza un municipio en la creación o compra de activos fijos y para mejorar el desarrollo humano y el bienestar. Considerando que este tipo de gasto tiene mayor capacidad para potenciar el crecimiento y el desarrollo, 
se esperaría que los valores más altos se encontraran en los municipios de mejor situación y los más bajos en los municipios más pobres, lo cual explicaría su desigual desarrollo; pero no es así, por el contrario, se ha encontrado que los municipios con mayor capacidad de inversión son precisamente los que se encuentran en peor situación. Es decir, gastar más no garantiza crecimiento y desarrollo. Y esto tiene que ver con la eficiencia de la administración pública municipal y la capacidad de las burocracias locales, que es muy cuestionable, sobre todo en los municipios medianos y pequeños.

También se ha elaborado otra categorización, a partir del PIB municipal, para ponderar el desigual reparto de la riqueza y su relación con la magnitud de los recursos públicos y la eficiencia con que se da el manejo financiero. Esto ha permitido observar que los municipios catalogados como "muy pobres" son los que tienen mayores recursos públicos por persona, en tanto que en los "ricos" y "muy ricos" esta proporción es considerablemente menor. Y esto es válido tanto para el caso del gasto total per cápita, como para los fondos federales de los ramos 28 y 33, que se transfieren a los municipios (participaciones per cápita y aportaciones per cápita). Lo anterior significa que los ayuntamientos más pobres gastan más recursos públicos por persona que los ricos, por lo que se esperaría que a lo largo del tiempo su situación fuera cambiando positivamente, pero los resultados no expresan un avance en su desarrollo. En cambio, los más ricos destinan montos de gasto público por persona menores, a pesar de lo cual sus resultados en términos de desarrollo son superiores.

Lo anterior no debe llevar a la conclusión de que el gasto público municipal no ejerce ningún efecto en el desarrollo, más bien debe conducir a considerar que su influencia depende del modo en que se administran los recursos y la manera en que se decide la asignación del gasto intramunicipal y, por ello, en los municipios más ricos se obtienen mejores resultados con menos recursos, mientras que en los pobres (con más gasto por persona) sucede lo contrario. Y muy probablemente esto es consecuencia de la menor eficiencia administrativa y una inadecuada asignación de los recursos.

También se ha estudiado la disponibilidad de los reglamentos municipales que les corresponde elaborar y aplicar a los ayuntamientos. Éstos son instrumentos legales útiles y necesarios para el desarrollo económico local. Se ha encontrado que existe una enorme carencia de normas municipales, lo que tiene un impacto negativo, ya que sin ellas muchos ayuntamientos son incapaces de impulsar el CE, mejorar el bienestar social y crear condiciones adecuadas para el desarrollo. 


\section{REFERENCIAS BIBLIOGRÁFICAS}

Afonso, António; Ebert, Werner; Schuknecht, Ludge, y Thöne, Michael (2005), “Quality of public finances and growth", Working Paper Series 438, European Central Bank.

Barcelata, Hilario, y Cuevas, Ana María (2013), "La inequidad del reparto intramunicipal del FISM en Coatepec, Veracruz", en A. Sánchez, Integración social territorial y desarrollo. Hacia políticas públicas alternativas, México, AMECIDERUNAM, s.p.

Barro, Robert J. (1990), "Goverment Spending in a Simple Model of Endogenous Growth", Journal of Political Economy, 98 (5), pp. 103-125.

Cabrero, Enrique (2004) "Capacidades institucionales en gobiernos subnacionales de México ¿un obstáculo para la descentralización fiscal?", Gestión y Política Pública, 13 (3), pp. 753-784.

Ceconi, Tulio Alberto (1998), "La fundamentación de una política de gasto público en base a la teoría del crecimiento económico", ponencia a las Terceras Jornadas "Investigaciones en la Facultad" de Ciencias Económicas y Estadística, Universidad de Rosario, octubre.

Devarajan, Shantayanan y Zou, Heng-fu (1994), "Does public Investment Promote Economic Growth?", working paper, The Hong Kong University of Science and Technology.

Esfahani, Hadi Salehi, y Ramírez, María Teresa (2003), "Institutions, Infrastructure, and Economic Growth", Journal of Development Economics, 70 (2), pp. 443-477.

Esquivel, Gerardo; López, Luis, y Vélez, Roberto (2003), "Crecimiento económico, desarrollo humano y desigualdad regional en México 1950-2000", en PNUD (ed.) Estudios sobre desarrollo humano, 3, México, PNUD., pp. 1-28.

Filmer, Deon, y Pritchett, Leon (1999), "The impact of public spending on health: does money matter?", Social Science \& Medicine, 49 (10), pp. 1309-1323.

García, Nubia (2014), La autonomía financiera, las capacidades administrativas y el diseño institucional en la contratación de deuda pública municipal, México, CEFP.

Gupta, Sanjeev; Verhoeven, Marijn, y Tiongson, Erwin (2001), "Public spending on health care and the poor", working paper, International Monetary Fund.

Hernández, Luis (2010), “Inversión pública y crecimiento económico: Hacia una nueva perspectiva de la función del gobierno", Economía: Teoría y Práctica, 0 (33), 59-95.

Herrera, Santiago, y Pang, Gaobo (2005), "Efficiency of public spending in developing 
countries: an efficiency frontier approach", Working Paper Series 3645, The World Bank.

Instituto Nacional de Estadística y Geografía (2005), "Estadísticas de finanzas públicas estatales y municipales", en Sistema Municipal de bases de datos SIMBAD. Consultado el 15 de enero de 2010, en: http://sc.inegi.org.mx/cobdem/contenido. jsp?rf=false\&solicitud.

(2009a), "Encuesta Nacional de Gobierno, Seguridad Pública y Justicia Municipal", en Censos de gobierno. Consultado el 15 de enero de 2010, en: www.inegi. org.mx/est/contenidos/proyectos/censosgobierno/engspjm/default.aspx.

- (2009b), "Sistema Municipal de Bases de Datos, SIMBAD", en Banco de datos. Consultado el 15 de enero de 2010, en: http://sc.inegi.org.mx/cobdem/.

Jayasuriya, Ruwan, y Wodon, Quentin (2003) "Measuring and Explaining Country Effciency in Improving Health and Education Indicators", en R. Jayasuriya y $Q$. Wodon (eds.), Efficiency in Reaching the Millennium Development Goals, World Bank Working Paper 9, Washington, The World Bank, pp. 5-16.

Lindauer, David L., y Velenchik, Ann D. (1992), "Government spending in developing countries. Trends, Causes, and Consequences", The World Bank Research Observer, 7 (1), pp. 59-78.

North, Douglas (1984), Estructura y cambio en la historia económica, Madrid, Alianza Editorial.

- (2006), Instituciones, cambio institucional y desempeño económico, México, Fondo de Cultura Económica.

Otero, Raúl (2011), Política fiscal municipal con federalismo cooperativo hacendario (El sistema catastral como estrategia para incrementar la recaudación predial), México, CEFP.

Peña, José Antonio, y Bojórquez, Ana Laura (2012), Autonomía financiera municipal, México, Instituto Nacional para el Federalismo y el Desarrollo Municipal-Secretaría de Gobernación.

Programa de las Naciones Unidas para el Desarrollo (2005), Informe sobre el Desarrollo Humano, México, PNUD.

Ranis, Gustav; Stewart, Frances, y Ramirez, Alejandro (2000), "Economic Growth and Human Development", World Development. 28 (2), pp. 198-210.

Ranis, Gustav y Stewart, Frances (2002), "Economic growth and human development in Latin America", CEPAL Review, (0) 78, pp. 7-23.

(2007), "Dynamic Links between the Economy and Human Development", en J. A. Ocampo, K. S. Jomo y K. Sarbuland (eds.), Policy Matters: Economic and Social Policies to Sustain Equitable Development, London, Zed Books, pp. 32-52. 
Sen, Amartya (2001), "Las teorías del desarrollo en el siglo XXI", Leviatán: Revista de Hechos e Ideas, 0 (84), pp. 65-84.

Scott, John (2011), “Gasto público y desarrollo humano en México. Análisis de incidencia y equidad", documento de trabajo para el Informe sobre desarrollo humano 2010, del PNUD.

$\mathrm{Xu}, \mathrm{Ke}$; Evans, David; Kawabata, Kei; Zeramdini, Riadh; Klavus, Jan, y Murray, Christopher (2003) "Household catastrophic health expenditure: a multicountry analisis", The Lancet, 362 (12 de julio), pp. 111-117. 